\title{
Electron Probe Microanalysis in Geosciences: Analytical Procedures and Recent Advances
}

\author{
Shui-Yuan Yang, ${ }^{\mathrm{a}, *}$ Shao-Yong Jiang, ${ }^{\text {a,b }}$ Qian Mao, ${ }^{\mathrm{c}}$ Zhen-Yu Chen, ${ }^{\mathrm{d}}$ Can Rao,${ }^{\mathrm{e}}$ Xiao-Li Li, ${ }^{\mathrm{f}}$ Wan-Cai Li, ${ }^{\mathrm{g}}$ \\ Wen-Qiang Yang, ${ }^{\text {h }}$ Peng-Li He, ${ }^{\text {i }}$ and Xiang $\mathrm{Li}^{\mathrm{j}}$ \\ ${ }^{a}$ State Key Laboratory of Geological Processes and Mineral Resources, China University of Geosciences, Wuhan 430074, P. R. China \\ ${ }^{\mathrm{b}}$ School of Earth Resources and Collaborative Innovation Center for Scarce and Strategic Mineral Resources, China University of Geosciences, Wuhan \\ 430074, P. R. China \\ ${ }^{\mathrm{c}}$ State Key Laboratory of Lithospheric Evolution, Institute of Geology and Geophysics, Chinese Academy of Sciences, Beijing 100029, P. R. China \\ ${ }^{\mathrm{d}}$ Institute of Mineral Resources, Chinese Academy of Geological Sciences, Beijing 100037, P. R. China \\ ${ }^{\mathrm{e}}$ Key Laboratory of Geoscience Big Data and Deep Resource of Zhejiang Province, School of Earth Sciences, Zhejiang University, Hangzhou 310027, P.R. \\ China \\ ${ }_{\mathrm{f}}^{\mathrm{f}}$ MOE Key Laboratory of Orogenic Belts and Crustal Evolution, School of Earth and Space Sciences, Peking University, Beijing 100871, P. R. China \\ ${ }^{g}$ CAS Key Laboratory of Crust-Mantle Materials and Environments, School of Earth and Space Sciences, University of Science and Technology of China, \\ Hefei 230026, P. R. China \\ ${ }^{\text {h }}$ State Key Laboratory of Continental Dynamics, Department of Geology, Northwest University, Xi'an, 710069, P. R. China \\ ${ }^{i}$ State Key Laboratory of Isotope Geochemistry, Guangzhou Institute of Geochemistry, Chinese Academy of Sciences, Guangzhou 510640, P.R. China \\ ${ }^{j}$ State Key Laboratory of Ore Deposit Geochemistry, Institute of Geochemistry, Chinese Academy of Sciences, Guiyang 550081, P. R. China
}

Received: October 07, 2021; Revised: December 31, 2021; Accepted: January 03, 2022; Available online: January 09, 2022.

DOI: 10.46770/AS.2021.912

ABSTRACT: Electron probe microanalysis (EPMA) is an in-situ and non-destructive analytical technique with high spatial resolution and an increasingly important analysis tool in materials science and geosciences. This study summarizes the principles and functions of EPMA, and the problems and difficulties, along with the recent advances in quantitative analysis of EPMA. A routine EPMA procedure includes preparing samples, setting analytical conditions, acquiring data, and evaluating results. Caution is required in all steps to obtain high-quality analytical results. The problems and difficulties commonly encountered in EPMA are discussed and the corresponding measures and solutions required to resolve them are proposed. Specific analytical methods are suggested to make accurate analysis of some specific minerals. We also summarized the challenges and solutions in light element analysis, trace element analysis, EPMA U-Th-Pb total dating, combined analysis with wavelength- and energy-dispersive X-ray spectroscopy, submicron spatial resolution analysis at low accelerating voltages, iron oxidation state analysis, and standard reference materials.
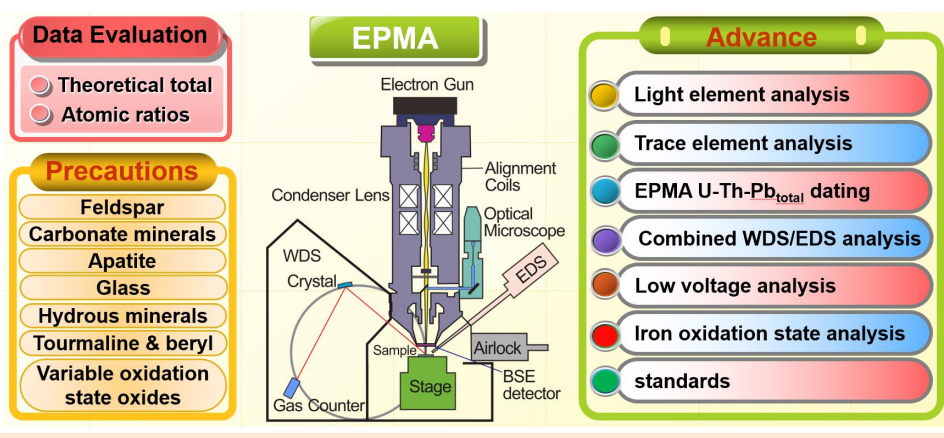

\section{INTRODUCTION}

Electron probe microanalysis (EPMA) is a modern technique based on the physical mechanism of electron-stimulated X-ray emission and X-ray wavelength-dispersive spectroscopy (WDS), which Raymond Castaing developed as part of his Doctor of Philosophy dissertation in Paris back to $1951 .{ }^{1}$ It is one of the most useful microanalytical methods for precise, non-destructive, and quantitative elemental analyses of solid materials, including 
metal alloys, glasses, ceramics, and minerals, at micrometer scale. The EPMA instrument can also be used for elemental line scan and mapping along with image acquisition, such as backscattered electron image (BSEI), secondary electron image (SEI) and cathodoluminescence (CL) image. Therefore, EPMA is a widely used technique with a significant impact on research in materials science $^{2}$ and geosciences. ${ }^{3}$

Previous studies ${ }^{2-8}$ provided some overviews on the principles, functions, analytical procedures, and instrumental and methodological developments of EPMA in geosciences. As the most commonly applied analytical technique in geosciences, we focused on recent advances in quantitative EPMA in geoscience in this study and emphasized on the following: 1) precautions that need to be considered when preparing samples and setting experimental conditions and evaluation of data quality and 2) challenges and solutions in EPMA, such as the analyses of light and trace elements, U-Th-Pbtotal dating, combined WDS and energy dispersive spectrometer (EDS) analysis, a higher spatial resolution, iron oxidation state analysis, and standard reference materials, aiming to further extend its applications in geosciences.

\section{PRINCIPLES AND FUNCTIONS}

There are several major EPMA instrument manufacturers, such as JEOL (Japan), Shimadzu (Japan), and CAMECA (France). An EPMA instrument comprises several components, including electron gun, electron lenses, sample stage, EDS, WDS, BSE detector (Fig. 1a). From the area on the sample surface bombarded by the electron beam, various signals, such as backscattered electrons, secondary electrons, characteristic X-rays, CL, transmitted electrons, and Auger electrons (Fig. 1b), are generated, detected, and processed in the EPMA to produce information on images (such as BSEI and SEI), chemical compositions, and structures. ${ }^{6}$ When the incident electron energy is greater than critical excitation energy of the element, the electron in the inner electron layer of the orbit is removed, creating an electron vacancy. Subsequently, the outer electrons of the excited state in the high-energy shell are transferred to the inner low-energy shell electron layer (Fig. 1c), and the characteristic X-rays with specific energy are emitted. The $\mathrm{X}$-rays emitted are known as continuous X-rays when the incident electrons are decelerated under the nuclear Coulomb field without removing an electron.

The main functions of EPMA include imaging, quantitative analysis, qualitative analysis, line scan, and elemental mapping. ${ }^{6}$ The types of images include BSEI and SEI, the former is a function of the mean atomic number of the materials and is mainly used to demonstrate the compositional differences, whereas the later (SEI) is used to display the sample surface

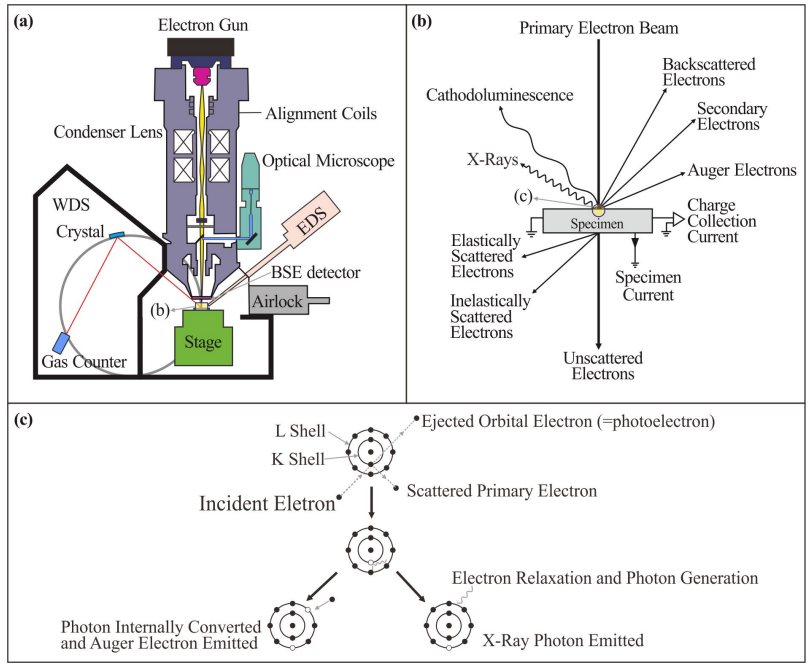

Fig. 1 A schematic diagram of (a) basic components of an electron probe microanalyzer (Modified after Llovet et $_{\text {al. }}{ }^{2}$ ), (b) signals geted by electron irradiation of the sample (Modified after $\mathrm{JEOL}^{10}$ ), and (c) the characteristic X-ray emission (after Goldstein $e t$ al. ${ }^{7}$ ).

morphologies. Qualitative analysis involves identifying and semi-quantifying most elements (theoretically from Be to $\mathrm{U}$ ) in the analyzed area or line. Line scan and mapping are essential in acquiring concentration variation of the element of interest within a line segment and a selected area in the sample, respectively. Furthermore, mapping provides an intuitive image of the element distribution within the area of interest. Accurate quantitative analysis of elements is the most essential EPMA application in geosciences, which is discussed in the subsequent section.

\section{QUANTITATIVE ANALYSIS}

Quantitative analysis by EPMA can be accomplished through both EDS and WDS. Although EDS is comparatively faster, it has a less energy resolution and a worse ability to detect elements present in low concentrations when compared to WDS. ${ }^{2}$ Therefor, we focused on WDS in this study. According to Moseley's law, ${ }^{9}$ wavelength $(\lambda)$ of the elemental characteristic X-rays is related to its atomic number $(Z),{ }^{7}$ as shown in equation (1):

$$
\lambda=\frac{B}{(Z-C)^{2}}
$$

where $\mathrm{B}$ and $\mathrm{C}$ are constants. Therefore, the wavelength of a characteristic X-ray emitted from a sample can be used to identify the elements present in the sample.

A WDS spectrometer utilizes a diffracting crystal to diffract the characteristic X-rays generated from the electron beam and sample interaction, which are subsequently detected by a gas flow or sealed proportional X-ray counter. The X-ray source in the sample, the diffracting crystal, and the proportional counter defines a circle known as Rowland circle with a constant 
Table 1. Diffracting crystals for the common elements

\begin{tabular}{|c|c|c|c|c|c|}
\hline \multirow{2}{*}{ Manufacturer } & \multirow{2}{*}{ Crystal } & \multirow{2}{*}{$2 \mathrm{~d}(\mathrm{~nm})$} & \multicolumn{3}{|c|}{ Analysis elements } \\
\hline & & & $\mathbf{K}$ & $\mathbf{L}$ & $\mathbf{M}$ \\
\hline \multirow{9}{*}{ JEOL } & LIF & \multirow{3}{*}{0.4027} & $\mathrm{~K} \sim \mathrm{Rb}$ & $\mathrm{Cd} \sim \mathrm{U}$ & \\
\hline & LIFL & & $\mathrm{K} \sim \mathrm{Br}$ & $\mathrm{Cd} \sim \mathrm{Fr}$ & \\
\hline & LIFH & & $\mathrm{Ca} \sim \mathrm{Ga}$ & $\mathrm{Sn} \sim \mathrm{Au}$ & \\
\hline & PET & \multirow{3}{*}{0.8742} & $\mathrm{Al} \sim \mathrm{Mn}$ & $\mathrm{Kr} \sim \mathrm{Tb}$ & $\mathrm{Yb} \sim \mathrm{U}$ \\
\hline & PETL & & $\mathrm{Al} \sim \mathrm{Cr}$ & $\mathrm{Kr} \sim \mathrm{Sm}$ & $\mathrm{Yb} \sim \mathrm{U}$ \\
\hline & PETH & & $\mathrm{Si} \sim \mathrm{Ti}$ & $\mathrm{Rb} \sim \mathrm{Ba}$ & $\mathrm{Hf} \sim \mathrm{U}$ \\
\hline & TAP & \multirow{3}{*}{2.5757} & $\mathrm{O} \sim \mathrm{P}$ & $\mathrm{Cr} \sim \mathrm{Nb}$ & $\mathrm{La} \sim \mathrm{Au}$ \\
\hline & TAPL & & $\mathrm{O} \sim \mathrm{Si}$ & $\mathrm{Cr} \sim \mathrm{Sr}$ & $\mathrm{La} \sim \mathrm{Re}$ \\
\hline & TAPH & & $\mathrm{F} \sim \mathrm{Al}$ & $\mathrm{Cr} \sim \mathrm{Br}$ & $\mathrm{La} \sim \mathrm{Yb}$ \\
\hline \multirow{4}{*}{ Shimadzu } & $\mathrm{LiF}$ & 0.401 & $\mathrm{Ca} \sim \mathrm{Ge}$ & $\mathrm{Sn} \sim \mathrm{Hg}$ & \multirow{4}{*}{$\begin{array}{l}\mathrm{Lu} \sim \mathrm{U} \\
\mathrm{Dy} \sim \mathrm{U}\end{array}$} \\
\hline & PET & 0.874 & $\mathrm{Si} \sim \mathrm{Ti}$ & $\mathrm{Kr} \sim \mathrm{Ba}$ & \\
\hline & $\mathrm{ADP}$ & 1.064 & $\mathrm{Al} \sim \mathrm{Ca}$ & $\mathrm{As} \sim \mathrm{Te}$ & \\
\hline & RAP & 2.612 & $\mathrm{O} \sim \mathrm{Al}$ & $\mathrm{Cr} \sim \mathrm{Kr}$ & \\
\hline \multirow{7}{*}{ CAMECA } & TAP & \multirow{3}{*}{2.576} & $\mathrm{~F} \sim \mathrm{P}$ & $\mathrm{Mn} \sim \mathrm{Mo}$ & $\mathrm{La} \sim \mathrm{Hg}$ \\
\hline & LTAP & & $\mathrm{F} \sim \mathrm{P}$ & $\mathrm{Mn} \sim \mathrm{Mo}$ & $\mathrm{La} \sim \mathrm{Hg}$ \\
\hline & $\begin{array}{l}\text { Extend TAP/ } \\
\text { Extend LTAP }\end{array}$ & & $\mathrm{O} \sim \mathrm{P}$ & $\mathrm{Cr} \sim \mathrm{Mo}$ & $\mathrm{La} \sim \mathrm{Hg}$ \\
\hline & PET & \multirow{2}{*}{0.8762} & $\mathrm{Si} \sim \mathrm{Mn}$ & $\mathrm{Sr} \sim \mathrm{Tb}$ & $\mathrm{Ta} \sim \mathrm{Am}$ \\
\hline & LPET & & $\mathrm{Si} \sim \mathrm{Mn}$ & $\mathrm{Sr} \sim \mathrm{Tb}$ & $\mathrm{Ta} \sim \mathrm{Am}$ \\
\hline & $\mathrm{LiF}$ & \multirow{2}{*}{0.4207} & $\mathrm{Sc} \sim \mathrm{Rb}$ & $\mathrm{Te} \sim \mathrm{Am}$ & \\
\hline & LLiF & & $\mathrm{Sc} \sim \mathrm{Rb}$ & $\mathrm{Te} \sim \mathrm{Am}$ & \\
\hline
\end{tabular}

diameter (Fig. 2a). The diffracting crystals diffract the characteristic X-rays when they satisfy Bragg's law (Fig. 2b; equation 2):

$$
\mathrm{n} \lambda=2 \mathrm{~d} \sin \theta
$$

where $\mathrm{n}, \lambda, \mathrm{d}$, and $\theta$ correspond to diffraction order (an integer), wavelength $(\AA)$ of the X-rays, interplanar spacing $(\mathrm{nm})$ of the diffracting crystal, and diffraction angle of the X-rays, respectively. The characteristic $\mathrm{X}$-ray wavelength depends on the element present in the sample, while the X-ray intensity is related to the concentration of the element. With the movement of the diffracting crystals and the proportional counter in a Rowland circle, the X-ray diffraction angle is adjusted within a specific range to diffract the characteristic $X$-rays with certain wavelengths onto the X-ray counter. In addition, a diffracting crystal can only diffract one characteristic X-ray line at a time. A

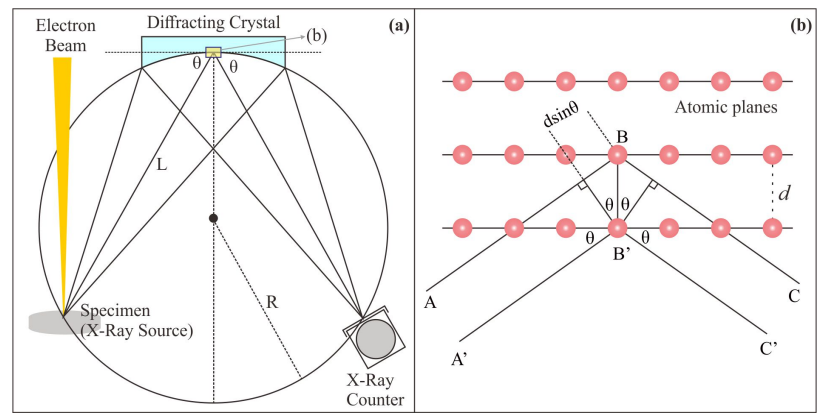

Fig. 2 A schematic diagram of (a) Rowland circle and (b) Bragg's diffraction law (after Reed ${ }^{6}$ ). R: radius of the Rowland circle; L: detection position, which is the distance between the X-ray source and the diffracting crystal; $\theta$ : diffraction angle at which the diffracted characteristic X-rays are in phase (after Zhao et al. ${ }^{3}$ ). diffracting crystal with an appropriate interplanar spacing need to be selected for a specific characteristic X-ray line. Common diffracting crystals used by major instrument manufacturers are listed in Tables 1 and 2.

Quantitative analysis is based on a positive correlation between concentration of element and intensity of the corresponding characteristic X-ray. Given the concentration of a specific element in a standard, $C_{\text {std, }}$, the concentration of the same element in an unknown sample, $\mathrm{C}_{\text {unk }}$, can be calculated using the formula presented in equation (3): ${ }^{6}$

$$
\mathrm{C}_{\text {unk }}=\frac{\mathrm{I}_{\text {unk }}}{\mathrm{I}_{\text {std }}} \times \mathrm{C}_{\text {std }} \times \frac{\mathrm{ZAF}_{\text {unk }}}{\mathrm{ZAF}_{\text {std }}}=\mathrm{k} \times \mathrm{C}_{\text {std }} \times \frac{\mathrm{ZAF}_{\text {unk }}}{\mathrm{ZAF}_{\text {std }}}
$$

where $\mathrm{I}_{\text {unk }}$ is the net intensity of the characteristic X-rays from the unknown sample, $I_{\text {std }}$ is the net intensity of the same characteristic $\mathrm{X}$-rays from the standard, and $\mathrm{ZAF}_{\text {unk }}$ and $\mathrm{ZAF}_{\text {std }}$ are the matrix correction factors of the unknown sample and standard, respectively. The $\mathrm{k}$ refers to the ratio of the unknown intensity to the standard intensity, known as k-ratio.

\section{SAMPLE PREPARATION}

Polishing. Sample preparation for EPMA includes cutting, embedding, grinding, and polishing., ${ }^{2,3,6}$ A flat and well-polished sample surface is required for EPMA. The quality of polishing of a sample directly affects the accuracy of the analytical results. An irregular geometry of the sample surface could strengthen or reduce the collection of X-rays. Moreover, a poorly polished sample surface makes it hard to focus, leading to the loss of the characteristic X-ray intensity (Fig. 3) because the location where an electron beam bombards the sample may be out-of-focus during analysis. ${ }^{10}$ The surface irregularities such as scratches or 


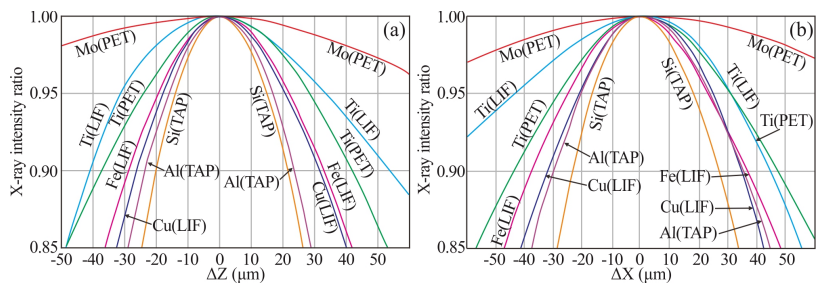

Fig. 3 The loss of characteristic X-ray intensity when the analytical position is out-of-focus (shift from Rowland Circle) in $\mathrm{Z}$ direction (a) and $\mathrm{X}$ direction (b) during analysis (after $\mathrm{JEOL}^{10}$ ).

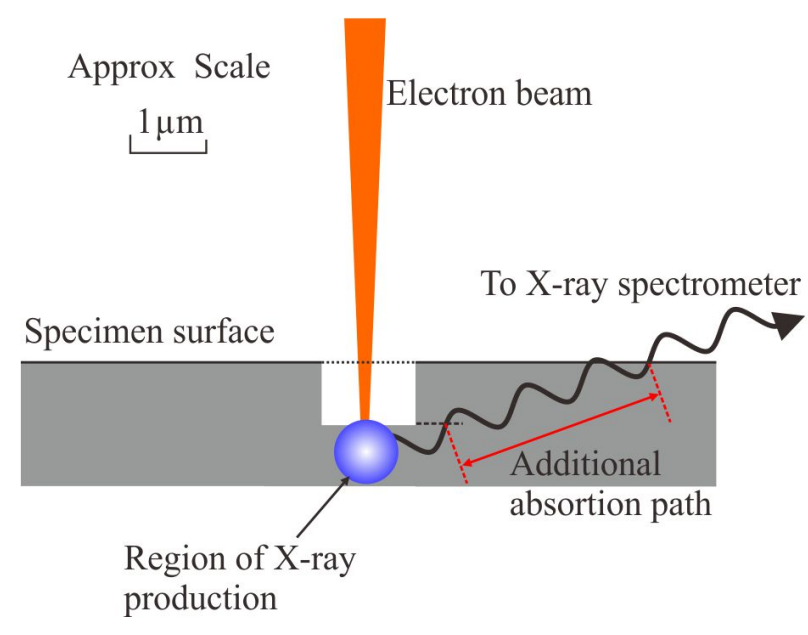

Fig. 4 A schematic diagram displaying the additional absorption produced by a pit on the sample surface (after Sweatman and Long ${ }^{8}$ ).

Table 2. Diffracting crystals for the light elements

\begin{tabular}{|c|c|c|c|}
\hline Manufacturer & Crystal & $2 d(n m)$ & Analysis elements \\
\hline \multirow{11}{*}{ JEOL } & STE & 10 & $\mathrm{~B} \sim \mathrm{O}$ \\
\hline & LDE1 & 6 & $\mathrm{C} \sim \mathrm{F}$ \\
\hline & LDE2 & 10 & $\mathrm{~B} \sim \mathrm{O}$ \\
\hline & LDEB & 14.5 & $\mathrm{Be} \sim \mathrm{B}$ \\
\hline & LDE1L & 6 & $\mathrm{C} \sim \mathrm{F}$ \\
\hline & LDE6L & 12 & $\mathrm{~B} \sim \mathrm{C}$ \\
\hline & LDE1H & 6 & $\mathrm{C} \sim \mathrm{O}$ \\
\hline & LDE2H & 10 & $\mathrm{~B} \sim \mathrm{C}$ \\
\hline & LDE3H & 20 & $\mathrm{Be} \sim \mathrm{B}$ \\
\hline & LDE5H & 8 & $\mathrm{C} \sim \mathrm{N}$ \\
\hline & LDE6H & 12 & $\mathrm{~B} \sim \mathrm{C}$ \\
\hline \multirow{7}{*}{ Shimadzu } & $\mathrm{PbST}$ & 10.02 & $\mathrm{~B} \sim \mathrm{N}$ \\
\hline & LSA55 & 5.5 & $\mathrm{C} \sim \mathrm{F}$ \\
\hline & LSA70 & 7.7 & $\mathrm{C} \sim \mathrm{O}$ \\
\hline & LSA80 & 8 & $\mathrm{~B} \sim \mathrm{N}$ \\
\hline & LSA 120 & 12 & $\mathrm{~B} \sim \mathrm{C}$ \\
\hline & LAS200 & 20 & $\mathrm{Be} \sim \mathrm{B}$ \\
\hline & LSA300 & 30 & $\mathrm{Be}$ \\
\hline \multirow{6}{*}{ CAMECA } & (L)PC0 & 4.5 & $\mathrm{~N} \sim \mathrm{Na}$ \\
\hline & (L)PC1 & 6 & $\mathrm{C} \sim \mathrm{F}$ \\
\hline & (L)PC2 & 10 & $\mathrm{~B} \sim \mathrm{O}$ \\
\hline & (L)PC3 & 20 & $\mathrm{Be} \sim \mathrm{B}$ \\
\hline & L Boron & 14.5 & B \\
\hline & L Nitrogen & 6 & $\mathrm{~N}$ \\
\hline
\end{tabular}

pits on the sample surface affect the number of the detected characteristic X-rays, especially the absorption of characteristic
X-ray by the samples. Fig. 4 shows the additional absorption of the characteristic X-ray by the sample around the pit on the sample surface owing to the extended trajectory of the characteristic X-ray. The additional absorption affects the detected intensity of the characteristic X-ray and absorption correction, generating spurious results. Furthermore, poorly polished sample surfaces have more severe effects on the analysis of light elements. ${ }^{8}$ Thus, the surfaces of the samples must be flat and unscratched to avoid surface morphology effects.

Coating. For electron microanalysis, a thin conductive film needs to be coated on the surface of non-conductive samples to prevent the charging effect on the sample surface and sample heating, ${ }^{11}$ which could affect detection of characteristic X-ray and image observation. The elemental composition of the coating material should be different from the element to be analyzed in the samples to minimize effect of coating on the analytical results. Carbon and some metals and alloys, for example, $\mathrm{Au}$ and $\mathrm{Au}-\mathrm{Pd}$ alloy, are commonly used for the sample surface coating. Gold has an atomic number of 79 and produces a complicated family of X-ray lines when interacting with an electron beam, thus strongly interfering with and absorbing the X-rays generated in the sample. Gold also affects the landing energy of the incident electron beam. Thus, gold coating is unsuitable for EPMA, although gold is often used to coat samples for SEM imaging. In contrast, carbon is a light element with an atomic number of 6 and is almost transparent to characteristic X-rays from the sample. Its effect on the X-rays from the sample is minimal and can be ignored during analysis. Therefore, carbon coating is used for EPMA. However, the effect of the carbon coating must be considered in the analysis of light elements or carbon-containing samples.

The thickness of the carbon coating affects the X-ray intensity. Kerrick et al. ${ }^{12}$ reported that the characteristic X-ray intensities of $\mathrm{F}, \mathrm{Si}, \mathrm{Fe}, \mathrm{Na}$, and $\mathrm{Sr}$ decreased with an increase in the thickness of the carbon film, especially for light elements (Fig. 5). Differences in the thickness of the carbon coating between the samples and standards lead to errors in the analytical results, especially for lower-energy X-rays. ${ }^{13,14}$ However, the loss of characteristic X-ray caused by the carbon film remains the same for the unknown sample and standard with similar carbon film thickness. Thus, it is essential to have the same thickness of the carbon coating on both the standards and samples for the quantitative analysis. Nevertheless, it is challenging to maintain the same thickness of the carbon coating for all thin sections loaded in the coating device even during the same evaporation process. Zhang and Yang $^{13}$ proposed a suitable method to minimize the difference in carbon film thickness during coating.

Unknown samples and standards are often coated at different times, which makes it difficult to coat them with the same carbon film thickness. Therefore, a mathematical model was proposed to 


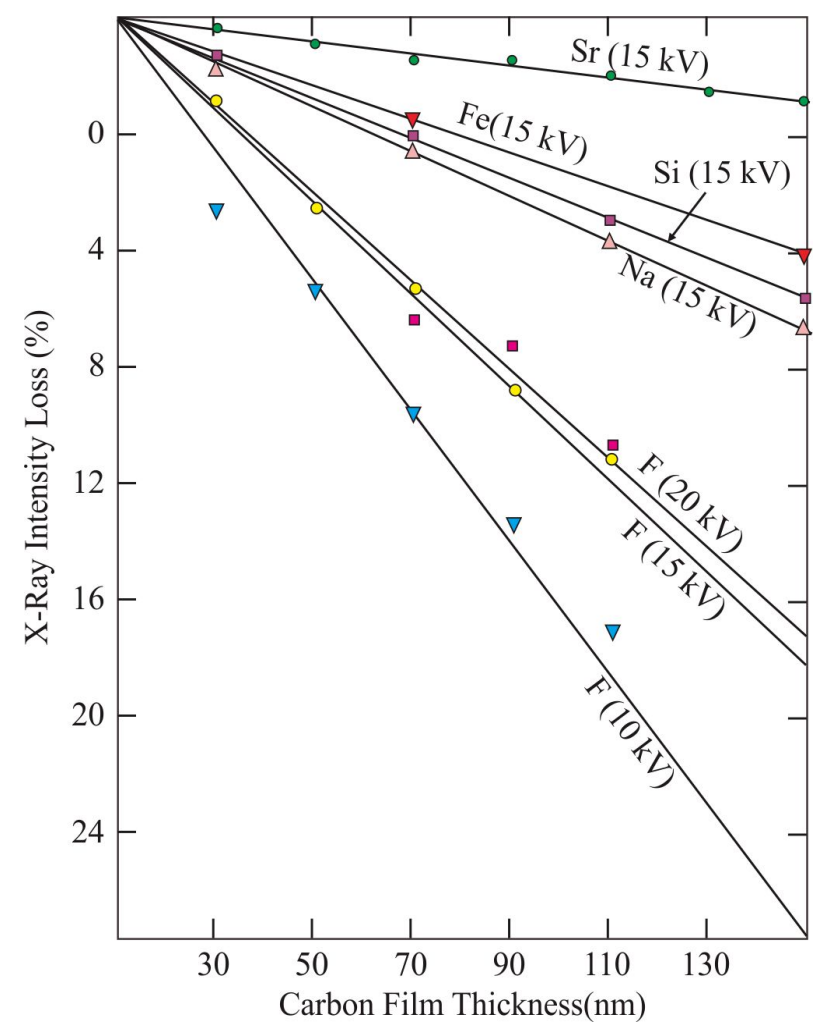

Fig. 5 The characteristic X-ray intensity loss with the increasing carbon film thickness (after Kerrick et al. ${ }^{12}$ ).

correct such errors to compensate for the changes in the characteristic X-ray intensity owing to different thicknesses of the carbon coating on the unknown sample and standard. ${ }^{15}$ This correction should be widely adopted to obtain accurate results, especially when using a low accelerating voltage or analyzing a light element.

\section{ANALYTICAL PROCEDURES AND EXPERIMENTAL CONDITIONS}

A peak search is required for the element of interest before the quantitative analysis, especially for the minor and trace elements, because the peak of the minor and trace elements cannot be searched in the sample during the analysis. These conditions include accelerating voltage, beam current, beam diameter, counting time, diffracting crystal, characteristic X-ray line, background, analysis sequence of elements, and standards.

Accelerating voltage. It is desirable to select an accelerating voltage higher than two times the critical excitation energy to improve the excitation efficiency of characteristic X-rays and obtain an ideal peak/background ratio. ${ }^{6}$ An accelerating voltage of $15 \mathrm{kV}$ is often used for analyzing oxides in geological samples, while $20 \mathrm{kV}$ is used for sulfide analysis (such as analyzing $\mathrm{Cu}$ and $\mathrm{Zn}$ in sulfide). Low and high accelerating voltages can be applied for light ${ }^{16,17}$ and trace elements, ${ }^{18}$ respectively, to obtain high counts.

Beam current. A high beam current increases the X-rays generated in the samples, thereby improving the precision of the analysis. However, the X-ray counts could exceed the upper limit of the X-ray counter in WDS when the beam current is high, leading to incorrect results. A beam current of $2 \times 10^{-8} \mathrm{~A}$ is effective for analyzing major elements in geological samples. However, a low beam current should be used when the migration of element occurs during the analysis, such as $\mathrm{Na}$ in feldspar. In contrast, a high beam current, up to $5 \times 10^{-7} \mathrm{~A}$ or $9 \times 10^{-7} \mathrm{~A},{ }^{18,19}$ can be used for analyzing trace elements.

Beam diameter. Beam diameter is often small (such as afocused beam or $1 \mu \mathrm{m}$ spot size) to improve spatial resolution. However, in some cases, a small beam spot could potentially damage the sample or cause the migration of the element. A large beam spot size is generally used when the element migration occurs during the analysis. Beam diameter used for the sample and standard analysis can be different when it is smaller than $20 \mu \mathrm{m}$. However, the beam diameter should be similar when it is larger than $20 \mu \mathrm{m}$ because a large beam spot reduces the characteristic X-ray intensity (Fig. 6). ${ }^{20}$

Additionally, the analytical area should be homogeneous. A heterogeneous area can yield inaccurate analytical results when a large beam is employed, partly because EPMA considers the analysis area homogeneous in the matrix correction process. ${ }^{2}$ For a heterogeneous area, the actual matrix where the emitted characteristic X-rays travel through is different from that used in the matrix correction procedure, ${ }^{6}$ leading to additional errors. ${ }^{10}$

Counting time. Counting time is the time used for measuring a peak or background. Background counting time is usually half of the peak counting time; however, it can be extended properly to improve the detection limit. Counting time varies depending on the concentrations of the elements. Peak counting time of major elements is usually from $10 \mathrm{~s}$ to $30 \mathrm{~s}$, while that of minor or trace elements can be from $30 \mathrm{~s}$ to $120 \mathrm{~s}$ to improve the precision. However, the counting time for migratory elements should be shorter.

Background. Continuous X-rays generated by bremsstrahlung radiation contribute to the background intensity in the WDS $\mathrm{X}$-ray spectra. These background X-rays are subtracted to obtain the net intensity of the characteristic X-rays. In a routine analysis, the background intensity is usually obtained through linear fitting according to the intensity measured on one side or both sides of the peak (Fig. 7a). However, the actual background may be curved (Fig. 7b), and a two-point linear fitting often results in errors, especially for light or trace element analyses. Methods such as two-point exponential, polynomial, or multi-point fittings ${ }^{19,21,22}$ can be applied for a better estimation of the background intensity. In addition, the mean atomic number 

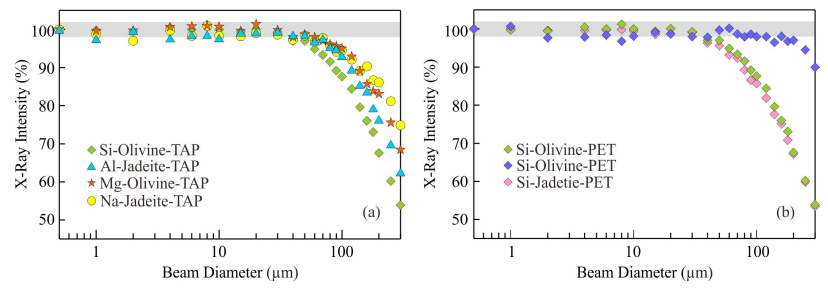

Fig. 6 A graph showing the changes in the detected characteristic X-ray intensity with the increasing beam diameter. ${ }^{20}$ (a) $\mathrm{Na}, \mathrm{Mg}, \mathrm{Al}$, and $\mathrm{Si}$ with a thallium acid phthalate (TAP) crystal and (b) Si in olivine and jadeite with a TAP and polyethylene terephthalate (PET) crystal. The gray area in the graph ranges from $98 \mathrm{wt} \%$ to $102 \mathrm{wt} \%$ on the vertical axis.
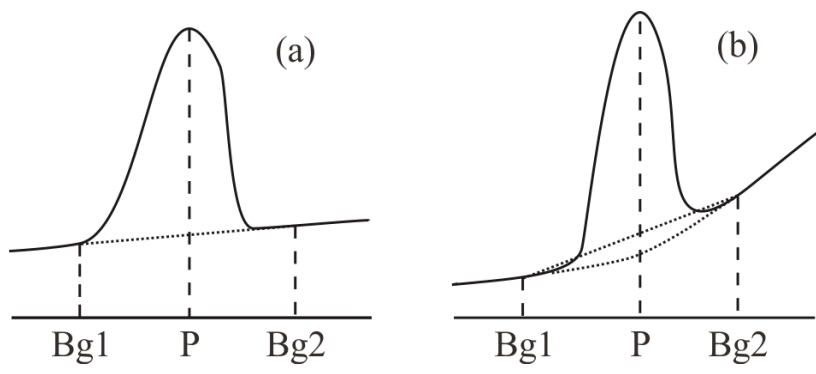

Fig. 7 A schematic diagram demonstrating the background intensity obtained by interpolation (Bg1 and Bg2): (a) linear fitting applicable when the background curvature is small; (b) linear fitting not applicable when the background curvature is large (after Reed ${ }^{6}$ ).

(MAN) background calibration curve method can be applied for the background intensity correction, ${ }^{23}$ acquiring the background intensity correction by measuring the peak intensities in a set of standards without the element of interest. This method can avoid the background measurement artifacts, thereby improving the measurement precision for the trace elements compared to traditional off-peak measurements.

Diffracting crystals. Diffracting crystals with different interplanar d spacings (Tables 1 and 2) are used to analyze different elements. A smaller d spacing is essential to obtain a better peak resolution in WDS. Counting rate and peak resolution should also be considered when selecting diffracting crystals. Counting rate increases when the diffraction angle is large, although the peak resolution may be poor. For example, distinguishing $\mathrm{Ce} \mathrm{L} \beta 1$ from $\mathrm{Nd} \mathrm{L} \alpha_{1}$ is difficult with PET crystals and easy with LIF crystals in the JEOL EPMA (Fig. 8).

Analysis sequence of elements. Elements that easily migrate under electron beam bombardments, such as $\mathrm{Na}, \mathrm{K}$, and $\mathrm{F}$, should be analyzed first. In addition, the analysis sequence of the elements should be arranged based on the diffraction angles from large to small or vice versa to improve the analytical efficiency and minimize movement and wearing of the WDS spectrometer.
Standard. Chemical compositions of standards are obtained through different analytical techniques, such as wet chemical analysis, X-ray fluorescence spectroscopy, and EPMA. It is ideal to select standards with the same chemical composition as the sample to minimize matrix effect. The concentrations of the elements to be calibrated in the standard should be sufficiently high to generate enough characteristic X-rays and ideally higher than that in the samples. In addition, the quality of a standard must be evaluated. For EPMA applications in geosciences, natural minerals are the most commonly used standards. ${ }^{24}$ Although these standards were previously evaluated as homogeneous by various analytical techniques, the quality, especially the homogeneity, may not be guaranteed. Thus, EPMA operators should examine the quality of standards in their laboratory and select appropriate standards accordingly.

\section{DATA EVALUATION AND INTERPRETATION}

Assuming all major elements are analyzed, and results are not normalized to $100 \mathrm{wt} \%$, the data quality of the quantitative EPMA is first evaluated by examining whether the total content of all measured elements is approximately $100 \mathrm{wt} \%$. Generally, the total analytical error of an EPMA instrument provided by the manufacturer is approximately $2 \mathrm{wt} \%$. Therefore, a total of $98 \mathrm{wt} \%-102 \mathrm{wt} \%$ is considered as a good result.

Theoretically, the total is $100 \mathrm{wt} \%$ when all elements are correctly measured during the quantitative EPMA. For example, the total for olivine, pyroxene, feldspar, and garnet is approximately $100 \mathrm{wt} \%$. However, the theoretical total is less than $100 \mathrm{wt} \%$ when some elements, such as $\mathrm{H}$ and $\mathrm{Li}$, are not measured. For example, hornblende and mica contain approximately $2.5 \mathrm{wt} \%$ and $4.5 \mathrm{wt} \% \mathrm{H}_{2} \mathrm{O}$, respectively, and the
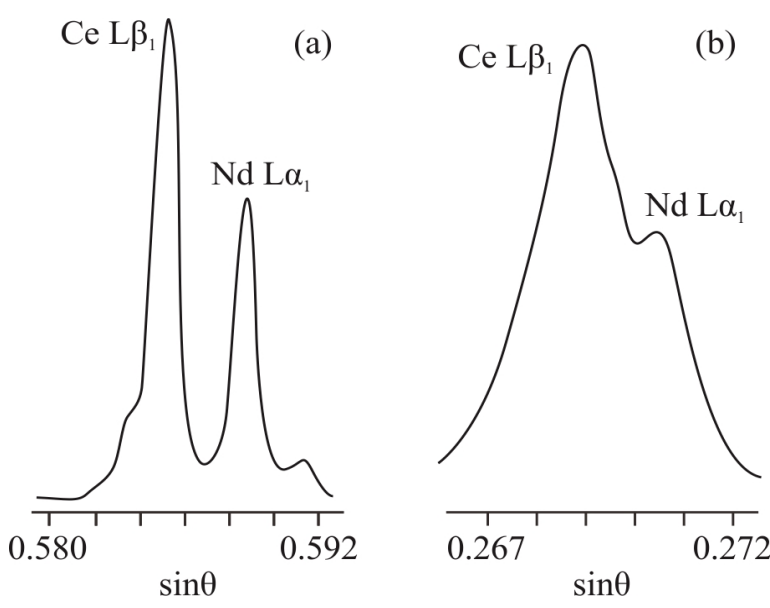

Fig. 8 The effect of the diffracting crystal on resolution in a wavelength dispersive (WD) spectra: peaks are recognizable with $\mathrm{LiF}$ (a); peaks are unrecognizable with PET (b) (after Reed ${ }^{6}$ ). 
theoretical total is approximately $97.5 \mathrm{wt} \%$ and $95.5 \mathrm{wt} \%$, respectively. An analytical total within the range of "theoretical total $-2 \mathrm{wt} \%$ " and "theoretical total $+1 \mathrm{wt} \%$ " is deemed suitable. The good analytical total is closer to the lower side due to the possible presence of unmeasured minor or trace elements.

Another criterion to evaluate the analytical results is by examining the atomic ratios or atomic \% according to the chemical formula of minerals. For example, the $\mathrm{S}$ atoms in pyrite $\left(\mathrm{FeS}_{2}\right)$ is $2 / 3$ of the total atoms. Additionally, the $\mathrm{Si}$ atoms in olivine $\left((\mathrm{Mg}, \mathrm{Fe})_{2}\left[\mathrm{SiO}_{4}\right]\right)$ is $1 / 3$ of the total cations.

Minor or trace elements have slight effect on the analytical total and atomic ratio. Therefore, it is difficult to determine the quality of their analytical result. A proper secondary standard containing the minor or trace elements analyzed in the sample can be measured during the sample analysis to evaluate the analytical quality of the minor or trace elements.

\section{ANALYTICAL PRECAUTIONS FOR SPECIAL MINERALS}

In geosciences, some minerals are special and require additional attention during the quantitative EPMA. They include: (1) minerals with migrant elements and time-dependent $\mathrm{X}$-ray intensities (TDI) during the analysis, such as feldspar, carbonates, apatite, glass, and hydrous minerals; (2) minerals containing light elements that are difficult to analyze, such as $\mathrm{C}$ in carbonate, $\mathrm{Be}$ in beryl, B in tourmaline, and hydrous minerals; and (3) minerals with variable oxidation-state oxides, such as magnetite, hematite, and cuprite. The precautions essential for these "special" minerals during the quantitative EPMA are described below.

Feldspar. Sodium and potassium in feldspar can easily migrate during EPMA, leading to underestimated $\mathrm{Na}$ and $\mathrm{K}$ contents and an overestimated $\mathrm{Si}$ and $\mathrm{Al}$ contents. Therefore, a low beam current $(10 \mathrm{nA})$ and a large beam spot (10 $\mu \mathrm{m}$ or more), is preferred during the analysis. Additionally, $\mathrm{Na}$ and $\mathrm{K}$ should be analyzed first. In addition to examining the analytical total, the atomic ratios should also be checked to evaluate the data quality. The atomic ratio of feldspar that can be used for the data quality evaluation includes $\mathrm{Na}+\mathrm{K}+2 \times \mathrm{Ca}=\mathrm{Al}$ and $3 \times \mathrm{Na}+3 \times \mathrm{K}+$ $2 \times \mathrm{Ca}=\mathrm{Si}$ (in cation number). The minerals or materials without TDI (such as homogenous jadeite standard) are preferred as the standard for Na. However, when albite minerals are selected as standards, it is necessary to decrease the beam current and increase the beam diameter to ensure that there are no TDI for $\mathrm{Na}$ during the standard analysis.

Carbonate minerals. Significant element migration under electron beam irradiation was also discovered in carbonate minerals. ${ }^{25-27}$ The optimized analytical conditions for carbonate minerals include a beam current of $5 \mathrm{nA}$ and beam diameter of $10 \mu \mathrm{m}$ for calcite; $10 \mathrm{nA}$ and $10 \mu \mathrm{m}$ for dolomite; $10 \mathrm{nA}$ and 5 $\mu \mathrm{m}$ or $20 \mathrm{nA}$ and $10 \mu \mathrm{m}$ for siderite; and $20 \mathrm{nA}$ and $5 \mu \mathrm{m}$ for other carbonates. ${ }^{25}$ Additionally, the easily migrated elements should be analyzed first. The carbon content is stoichiometrically calculated (such as the ratio of $\mathrm{C}: \mathrm{O}=1: 3$ ) based on their chemical formula $\left(\mathrm{MCO}_{3}\right.$, where $\mathrm{M}$ is a metal cation) or by fixing the $\mathrm{CO}_{2}$ content from the difference between $100 \mathrm{wt} \%$ and the $\mathrm{MO}$ content, and subsequently the $\mathrm{CO}_{2}$ content is included in the matrix correction. In addition, silicate minerals are more suitable than carbonate minerals to serve as standards for the carbonate mineral analysis. When carbonate minerals are selected as standards, it is also necessary to ensure that there are no TDI during the standard analysis.

Apatite. Fluorine in apatite shows strong TDI during the electron beam irradiation, ${ }^{28-31}$ especially when the incident electron beam is parallel to the c-axis of apatite (Fig. 9). A TDI correction model based on the mathematical relationship between the characteristic $\mathrm{X}$-ray intensity and time was proposed to measure the $\mathrm{F}$ content in apatite. ${ }^{31,32}$ The model extrapolates the X-ray intensity to the moment when the electron beam just arrives at the sample surface (time $=0$ ). In addition, it was proposed that cooling the samples with a liquid nitrogen cold trap in EPMA could reduce the TDI effect. ${ }^{33}$

However, not all laboratories can perform automated TDI correction and use liquid nitrogen cold traps due to software and hardware limitations. The following are the considerations for the quantitative EPMA of apatite:

(1) Avoid exposing apatite to a high electron beam current before analysis. Observe it with a low beam current and minimize the observation time.

(2) A low beam current and large beam diameter can be used to minimize the $\mathrm{F}$ migration. Analyze $\mathrm{F}$ and $\mathrm{Cl}$ first, with a short analytical time. ${ }^{30}$

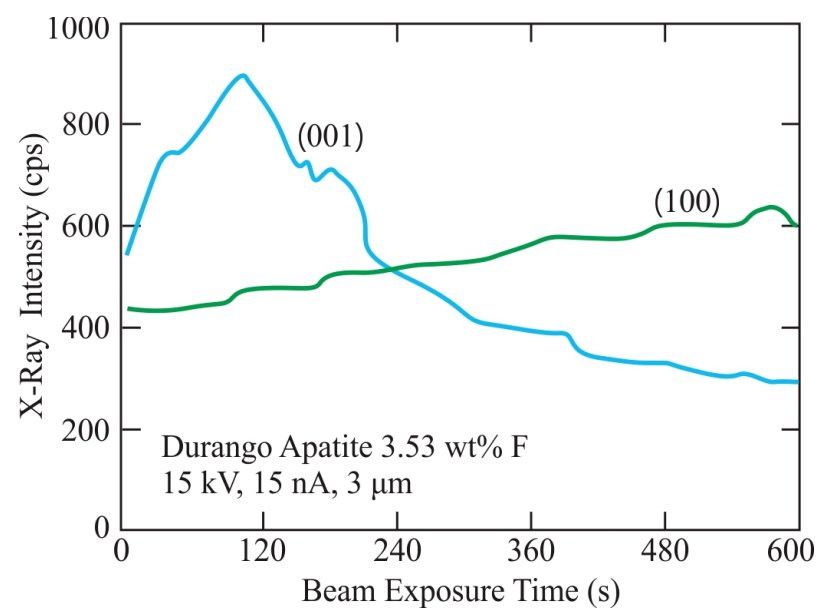

Fig. 9 The variation in the X-ray intensity of different crystal planes of fluorapatite with the exposure time of electron beam (Modified after Stormer et al..$^{31}$ ). 
(3) Polish apatite crystal such that its c axis is parallel to the polished surface since apatite exhibits less TDI effect in this direction. ${ }^{28}$

(4) Select diffracting crystals LDE1 (JEOL), PC1 (Cameca), and LSA55 (Shimadzu) for analyzing F since they have higher count rates than the traditional TAP crystals. It is necessary to select an appropriate background position for the measurement because the peak shape of $\mathrm{F}$ is broad when using these diffracting crystals.

(5) Utilize topaz, $\mathrm{BaF}_{2}, \mathrm{MgF}_{2}$, or materials with a weak TDI as the standard for analyzing F. Fluorine in apatite has strong TDI effect, which is not a good choice as a standard for analyzing $\mathrm{F}$ in apatite. ${ }^{30}$ Fluorite is also unsuitable as a standard for $\mathrm{F}$ in apatite because $\mathrm{F}$ in fluorite shows significant TDI.

(6) Examine the F concentration. According to the apatite chemical formula, the $\mathrm{F}$ concentration in the end member of fluorapatite is $3.77 \mathrm{wt} \%$. Thus, the $\mathrm{F}$ concentration in apatite higher than $3.77 \mathrm{wt} \%$ should be treated carefully.

Glass. Sodium and potassium in silicate glass also exhibit TDI under electron beam bombardment, particularly those in rhyolite or $\mathrm{H}_{2} \mathrm{O}$-bearing glass. ${ }^{34}$ Experimental conditions suitable for analyzing glass include reducing the current density by a lower beam current and utilizing a larger beam diameter, 20,34,35 conducting TDI correction, ${ }^{34}$ and analyzing at cryogenic temperatures. ${ }^{36}$

The following are the considerations for the EPMA of glass:

(1) Use a low beam current and a large beam diameter. When the beam diameter exceeds $20 \mu \mathrm{m}$, use the same beam diameter for both standards and samples.

(2) Determine whether the sample exhibits TDI under the selected conditions before analysis. Reduce the beam current and/or increase the beam diameter till the TDI is negligible when the sample demonstrates TDI effect.

(3) Analyze a secondary glass standard with a composition similar to the sample for data quality control or evaluation. Difference between $100 \mathrm{wt} \%$ and an actual total content obtained is often used to determine the concentrations of $\mathrm{H}_{2} \mathrm{O}$ or volatiles in glass. However, the difference may also arise due to the surface discharge of the sample ${ }^{37}$ or TDI. The $\mathrm{H}_{2} \mathrm{O}$ content calculated by the difference method must be involved in the matrix correction for glass samples with high $\mathrm{H}_{2} \mathrm{O}$ content.

Hydrous minerals. All the components in a sample, including $\mathrm{H}_{2} \mathrm{O}$, should be considered for the matrix corrections in quantitative EPMA. The total of hydrous minerals obtained by EPMA is less than $100 \mathrm{wt} \%$ because EPMA does not measure the $\mathrm{H}_{2} \mathrm{O}$ content. Matrix correction factors can be incorrect when $\mathrm{H}_{2} \mathrm{O}$ is not included in the matrix correction. However, the effect can be ignored for minerals with low $\mathrm{H}_{2} \mathrm{O}$ content, such as mica and hornblende. In contrast, inaccurate results can be obtained for minerals with high $\mathrm{H}_{2} \mathrm{O}$ content, such as chlorite, serpentine, and turquoise, when $\mathrm{H}_{2} \mathrm{O}$ is not considered in the matrix correction.

Tourmaline and beryl. The accurate EMPA of light elements is problematic due to the high absorption of the low energy X-rays and spectral interferences from higher-order X-ray lines of heavier elements. ${ }^{16}$ During the EPMA of tourmaline and beryl, B and $\mathrm{Be}$ are calculated instead of being measured. The chemical formula of tourmaline is $(\mathrm{Na}, \mathrm{Ca}, \mathrm{K}) \mathrm{R}_{3} \mathrm{~A}_{16}\left[\mathrm{Si}_{6} \mathrm{O}_{18}\right]\left(\mathrm{BO}_{3}\right)_{3}(\mathrm{O}, \mathrm{OH}, \mathrm{F})$ $(\mathrm{R}=\mathrm{Mg}, \mathrm{Fe}, \mathrm{Li}, \mathrm{Mn}, \mathrm{Cr}, \mathrm{V}$, or $\mathrm{Al}$ ) with approximately $10 \mathrm{wt} \%$ $\mathrm{B}_{2} \mathrm{O}_{3}$ while that of beryl is $\mathrm{Be}_{3} \mathrm{Al}_{2}\left[\mathrm{Si}_{6} \mathrm{O}_{18}\right]$ with approximately 14 wt $\% \mathrm{BeO}$. The contents of $\mathrm{B}_{2} \mathrm{O}_{3}$ and $\mathrm{BeO}$ can be calculated according to the atomic ratio $\mathrm{B}: \mathrm{Si}=1: 2$ and $\mathrm{Be}: \mathrm{O}=1: 6$ with $\mathrm{B}_{2} \mathrm{O}_{3}$ and $\mathrm{BeO}$ included in the matrix correction when $\mathrm{B}$ and $\mathrm{Be}$ are not measured directly by EPMA.

Variable oxidation state oxides. Concentrations obtained by quantitative EPMA are usually expressed as oxides of elements with oxygen calculated by stoichiometry, i.e., proportioning $\mathrm{O}$ according to the valence state of a cation and then participating in the matrix correction. Therefore, the valence states of the cations are determined before the analysis.

When a preset valence state of an element (such as Fe) does not match the actual valence state of the element in a mineral (such as magnetite), the calculated $\mathrm{O}$ content and the total will be incorrect. For example, the total obtained will be $1.6 \mathrm{wt} \%$ less than the theoretical total $100 \mathrm{wt} \%$ when the Fe valence is incorrectly set as +2 for hematite $\left(\mathrm{Fe}_{2} \mathrm{O}_{3}\right)$. In contrast, an accurate result is obtained when the Fe valence state is correctly set to +3.38 Iron in minerals of the spinel group, such as magnetite $\mathrm{Fe}^{2+} \mathrm{Fe}^{3+}{ }_{2} \mathrm{O}_{4}$, exists as both $\mathrm{Fe}^{3+}$ and $\mathrm{Fe}^{2+}$ in different proportions. It has been demonstrated that careful electron microprobe analyses with stoichiometry and charge balance for Fe-bearing minerals such as magnetite and ilmenite yield $\mathrm{Fe}^{3+} /\left(\mathrm{Fe}^{2+}+\mathrm{Fe}^{3+}\right)$ ratio similar to those from Mössbauer analyses, albeit with larger relative errors. ${ }^{39}$ However, the software provided by the instrument manufacturers may only allow an integer value to be input, creating an obstacle for analyzing oxides with variable oxidation states. In this case, cations with variable oxidation states can be analyzed and determined as a simple substance (setting the valence state to 0 ), and $\mathrm{O}$ can be calculated from difference and included in the matrix correction. ${ }^{38}$

\section{RECENT ADVANCES AND CHALLENGES IN EPMA}

Light element analysis. Light elements, such as Be, B, C, N, O, and F, emit low energy "soft X-rays" (energy less than $1 \mathrm{keV}$ ) (Table 3). Detection of these low energy soft X-rays, thereby 
Table 3. Characteristics of the light element $\mathrm{K} \alpha$ lines (after Goldstein et al. $\left.{ }^{7}\right)$

\begin{tabular}{lcccc}
\hline Element & Symbol & $\mathbf{Z}$ & $\boldsymbol{\lambda}(\AA)$ & $\mathbf{E}(\mathbf{k e V})$ \\
\hline Beryllium & $\mathrm{Be}$ & 4 & 114.0 & 0.109 \\
Boron & $\mathrm{B}$ & 5 & 67.6 & 0.183 \\
Carbon & $\mathrm{C}$ & 6 & 44.7 & 0.277 \\
Nitrogen & $\mathrm{N}$ & 7 & 31.6 & 0.392 \\
Oxygen & $\mathrm{O}$ & 8 & 23.62 & 0.525 \\
Fluorine & $\mathrm{F}$ & 9 & 18.32 & 0.677 \\
\hline
\end{tabular}
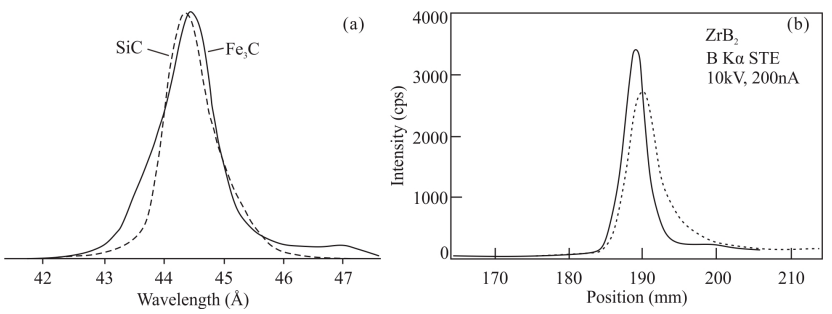

Fig. 10 (a) The peak shape of $\mathrm{C} \mathrm{K} \alpha$ peaks recorded from $\mathrm{SiC}$ and $\mathrm{Fe}_{3} \mathrm{C}$ with differences in position and shape (after Bastin and Heijligers ${ }^{43}$ ); (b) Two extremes of the $\mathrm{B} \mathrm{K} \alpha$ peak shape recorded from $\mathrm{ZrB}_{2}$ with the rotation of the specimen (after Bastin and Heijligers ${ }^{44}$ ).

determining light element concentrations by EPMA is challenging and is often less efficient and less accurate. These challenges include: (1) samples, diffracting crystals, and detector windows that absorb the low energy characteristic X-rays strongly; (2) reliable mass absorption coefficients of light elements remain to be determined; (3) low energy characteristic $\mathrm{X}$-rays are interfered by the X-rays generated from heavier elements; (4) peaks of characteristic X-rays from light elements shift and the peak shapes of the light elements change too in different matrices or compounds; (5) the lack of suitable light element standards; and (6) the carbon contamination and thickness difference of the carbon film on the sample surface.

Nevertheless, the accuracy and precision of the light element analysis can be improved through the following steps:

(1) Use a diffracting crystal with large d spacings, such as layered dispersion element (LDE, Table 2), to obtain significantly high counts and peak/background ratios.

(2) Use a suitable acceleration voltage for the light element analyses. For example, the intensity of Be in beryllium metal is the highest when the acceleration voltage is $12 \mathrm{kV} .{ }^{40}$ Although the intensity of the characteristic X-rays increases with increasing the acceleration voltage, a higher acceleration voltage also increases the depth of characteristic X-rays, causing a high absorption effect. ${ }^{16,40,41}$

(3) Minimize the effect of coating material, primarily carbon, on the characteristic X-rays of light elements. The conductive thin film coated on a sample surface can significantly absorb low-energy characteristic X-rays emitted by the light elements. Carbon contamination on the sample surface due to the heat from electron beam bombardment make the absorption effect even worse. ${ }^{15}$ Differences in the carbon film thickness between the standards and samples also lead to errors in the analytical results. Therefore, it is strongly recommended to use a liquid nitrogen cold trap for cooling, ${ }^{15,42}$ coat standards and samples with the same thickness of the carbon film, ${ }^{13}$ and correct uncertainties from carbon film thickness and counting rate to effectively alleviate the above-mentioned problems. ${ }^{15}$

(4) Consider effects of the peak shift and peak shape on the measured intensities. Changes in the peak shift and peak shape of a light element have been observed in a different matrix (Fig. 10a). ${ }^{43}$ Changes in the peak shape also occur in different crystallographic planes within the same mineral (Fig. 10b). ${ }^{16,44}$ The light element content obtained from the peak height will lead to erroneous results when effects of peak shifts and peak shape changes are not resolved,. The methods proposed in previous studies, ${ }^{44}$ such as peak area integral intensity and area/peak factor, can assist in obtaining more reliable results.

(5) Use an appropriate mass-absorption coefficient for and a primary standard similar to the composition of the unknown sample (preferably also similar in crystallographic orientation), which is crucial for the light element analysis. ${ }^{16,44}$

In addition, utilizing pulse height analysis for alleviating interference from heavier element ${ }^{40,45}$ and developing ultra-soft $\mathrm{X}$-ray spectrometer technology will also assist in analyzing light elements. $^{46,47}$

Trace element analysis. Trace element analysis using EPMA has gained extensive attention in recent years. The principal challenge is to effectively improve the detection limit and increase the accuracy and precision of the analytical results. The precision of the analysis is improved by increasing the accelerating voltage, beam current, and counting time. In most cases, a high accelerating voltage also helps improve the detection limit. Although a high beam current and long counting time improve precision, they can also cause TDI. ${ }^{19,48,49}$ Nevertheless, allocating the counting time to different locations on the homogeneous sample surface reduces the TDI effect, which is well utilized for analyzing glass and quartz. ${ }^{22,50}$ In addition, using large diffracting crystals and simultaneously analyzing the same element with multiple spectrometers improve the precision and detection limit. ${ }^{22,51}$

Factors affecting the trace element analysis include peak interference, background fitting, and secondary fluorescence effect. ${ }^{19,21}$ The peak interference is mainly caused by the low-order X-rays of some elements (Fig. 11a) and may be separated by overlapping the peak deconvolution and correction. ${ }^{30,52} \mathrm{~A}$ "step" is a sharp decline in the X-ray continuum background (Fig. 11b), ${ }^{6}$ and a "hole" is a negative peak in the X-ray continuum background (Fig. 12). ${ }^{22}$ The "steps" and "holes" observed in the background or underneath the peak also 

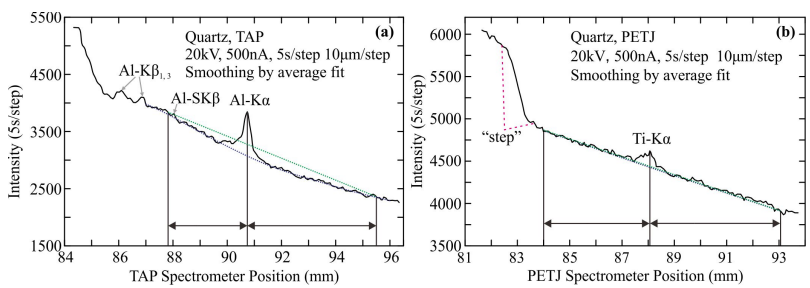

Fig. 11 Wavelength dispersive scans of quartz at the position for (a) the Al $\mathrm{K} \alpha$ peak exhibiting a curving background and (b) the $\mathrm{Ti} \mathrm{K} \alpha$ peak demonstrating "step" in the left background of Ti K $\alpha$ (after Cui et al..$^{19}$ ).

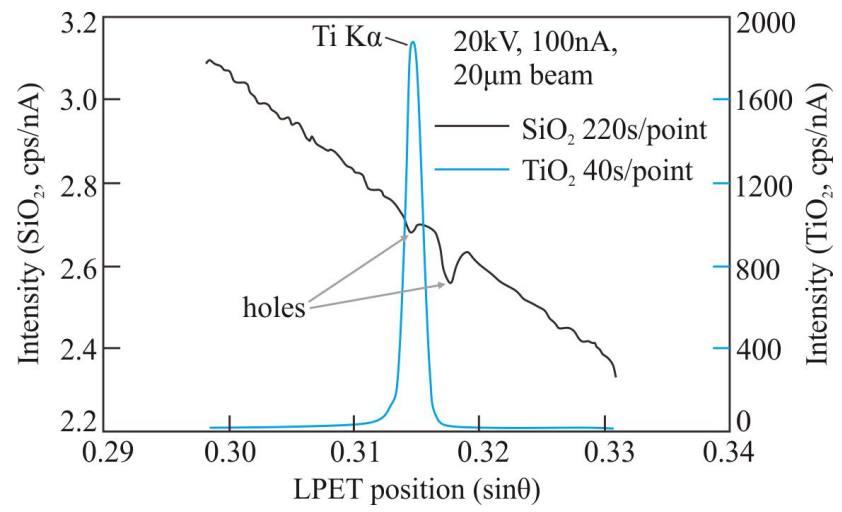

Fig. 12 Wavelength dispersive scans of $\mathrm{SiO}_{2}$ and $\mathrm{TiO}_{2}$ at the position for the Ti K $\alpha$ peak showing "holes" in the continuum, both adjacent to and directly underneath the analytical peak position (after Donovan et $a .^{22}$ ).

significantly affect the trace element analysis. Therefore, the interference peaks, "steps", "holes" and other interfering factors present in the background need to be avoided when selecting the background positions for analysis. The secondary fluorescence is the excitation of an element in an adjacent phase by the primary $\mathrm{X}$-rays from the measurement spot. This phenomenon can occur far away from the original measurement spot since X-rays penetrate very far, for example, a chromite host with an olivine inclusion when analyzing $\mathrm{Cr}$ in the olivine, ${ }^{3}$ or a neighboring rutile close to quartz when analyzing $\mathrm{Ti}$ in the quartz. ${ }^{48}$ This results in an overestimation of the concentration of the analyzed element. Therefore, it is essential to select the measurement spots with a sufficient distance from the neighboring mineral ${ }^{19,48}$ or utilize simulation software for correcting the secondary fluorescence effect to avoid or reduce secondary fluorescence effect. ${ }^{53-55}$ For elements with a curved background shape rather than a straight line, such as $\mathrm{Al} \mathrm{K \alpha}$ in quartz (Fig. 11a), a two-point exponential curve fitting for the background or a blank correction (measure a zero-concentration standard with a matrix similar to the unknown to obtain an accurate background intensity) is superior to a two-point background interpolation method. ${ }^{22}$ The multipoint background fitting is another effective method for fitting a curved background. ${ }^{19,21}$ In addition, the MAN method adopted by the Probe Software, an EMPA application software, is also a reliable fitting method for the background intensities. ${ }^{23}$ In an analytical procedure, a suitable secondary standard and a sample can be analyzed simultaneously to effectively monitor the accuracy of the results.

EPMA U-Th-Pbtotal dating. The EPMA U-Th-Pbtotal dating, also

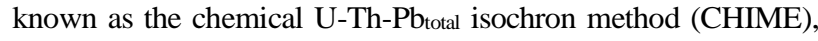
is widely applied for accessory minerals rich in $\mathrm{U}$ and $\mathrm{Th}$, such as zircon, monazite, xenotime, thorianite, and uraninite. ${ }^{56-59}$ This method assumes that the dating mineral system is closed (without the $\mathrm{Pb}$ loss), and the initial $\mathrm{Pb}$ content is negligible. The basic dating equation was continuously improved, and several methods were proposed, including isochron, average apparent age, three-dimensional fitting, and two-dimensional fitting methods. ${ }^{57,58,60,61}$ Theoretically, the initial $\mathrm{Pb}$ content can be estimated and corrected by applying isochron and three-dimensional fitting methods. However, its applications become problematic when the initial $\mathrm{Pb}$ is heterogeneously distributed in the minerals.

Since most accessory minerals have low contents of $\mathrm{U}$, Th, and $\mathrm{Pb}$ (mainly $\mathrm{Pb}$ ), high-quality measurements of these elements play a vital role in the CHIME dating method. ${ }^{62}$ However, analyzing $\mathrm{U}, \mathrm{Th}$, and $\mathrm{Pb}$ is a challenge for rare earth element-rich (REE-rich) minerals (such as zircon, monazite, and xenotime) due to the complex spectral characteristics of REEs that affect the $\mathrm{Pb}$ analysis. ${ }^{62,63}$ Hence, interference correction is essential when interferential elements exist in a sample. ${ }^{57}$ Some methods such as shared background measurement, multipoint background analysis, and MAN method can be used for background interference to obtain accurate backgrounds. ${ }^{21,23,64}$

Combined analysis with WDS/EDS. EDS and WDS are widely used in the microanalysis of major elements in minerals and materials. The application of silicon drift detector EDS (SDD-EDS) has greatly improved the EDS performance with the development of semiconductor detectors and improvement of EDS energy resolution. ${ }^{65}$ The SDD-EDS has high counts throughput and extremely high stability in terms of peak shape (resolution) and peak position (calibration), ${ }^{66}$ making it possible to utilize EDS for accurate quantitative analysis. Thus, EDS has become an analytical tool for the precise quantification of major elements (>1 wt $\%$ ) even when severe peak interference occurs. ${ }^{67-71}$ Moreover, trace elements analysis with EDS can obtain a detection limit of 250 ppm or less in the absence of peak interference. $^{68}$

The peak resolution of SDD-EDS is lower than that of the WDS, thereby limiting the determination of trace element content by EDS. However, the simultaneous analysis, short measurement time, and simple operation make EDS suitable for analyzing major elements, especially for easily migrated elements. A rapid and accurate component information of the sample can be obtained when a WDS with high resolution and low detection limit is combined with the simple and fast EDS.

In order to combine WDS and EDS, it is necessary to meet the 


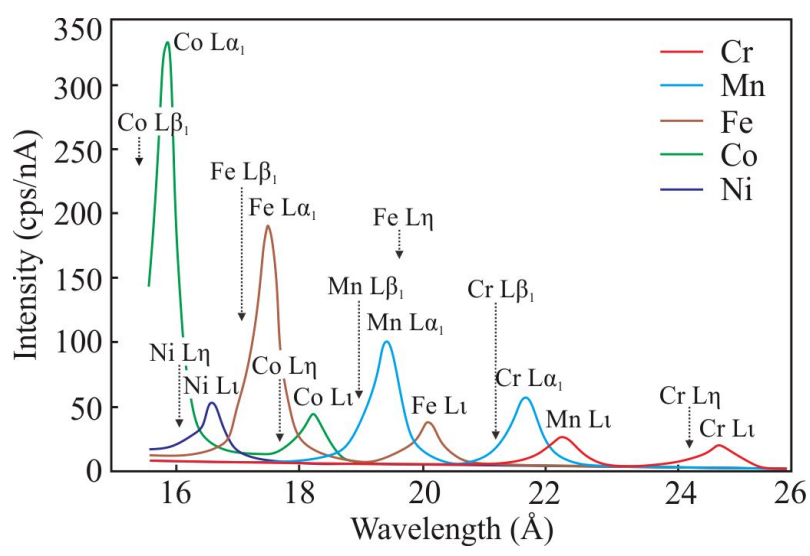

Fig. 13 Five wavelength-dispersive spectra acquired on pure standards of $\mathrm{Cr}, \mathrm{Mn}, \mathrm{Fe}, \mathrm{Co}$, and $\mathrm{Ni}$ at $5 \mathrm{kV}$ and $50 \mathrm{nA}$, using a LDE1 crystal (after Pinard and Richter $^{79}$ ).

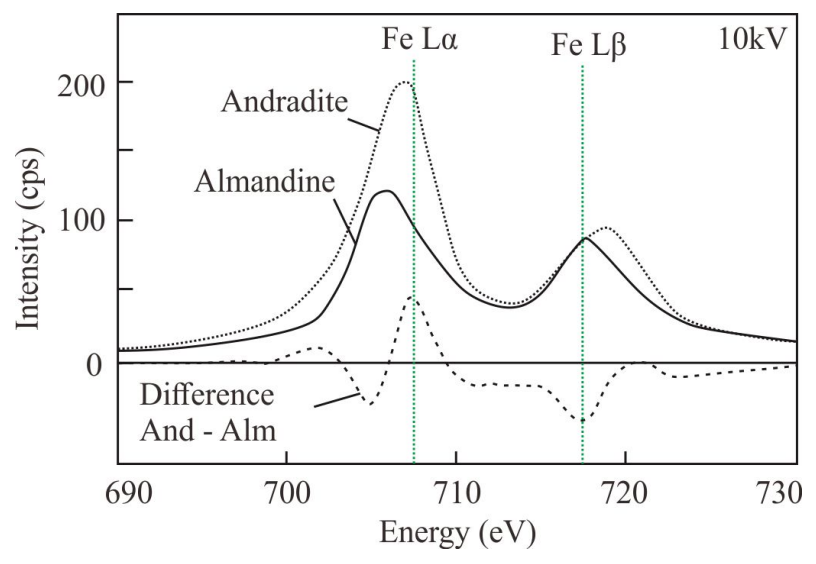

Fig. 14 Fe L X-ray emission spectra of almandine and andradite at $10 \mathrm{kV}$ with the difference spectrum. The "flank method" measurement positions ( $\mathrm{Fe} \mathrm{L} \alpha$ and $\mathrm{Fe} \mathrm{L} \beta$ ) are defined in the regions having the largest difference between spectra (after Höfer and Brey ${ }^{87}$ ).

requirements of the operating software to control the simultaneous working of WDS and EDS. In addition, suitable operation conditions should be established. The normal working conditions of WDS and EDS are different. WDS requires a large beam current to obtain a higher count rate, which generates high counts in EDS and leads to a long dead time. When WDS and EDS are combined, WDS can be used to analyze trace elements (0.01 wt \%-1 wt \%) and elements with overlapping peaks in EDS (such as the $\mathrm{L}$ line of $\mathrm{Ni}, \mathrm{Cu}$, and $\mathrm{Zn}$ ), while EDS can be used to analyze major elements. Thus, the advantages of WDS and EDS can be availed to improve the efficiency of analysis. ${ }^{72}$

Quantitative analysis at low accelerating voltages for improved spatial resolution. With field emission guns equipped in EPMA, large and steady beam currents under low accelerating voltages become available, ${ }^{2,6}$ leading to an improved spatial resolution down to submicron scale. The low accelerating voltage EPMA has been applied to study volcanic processes by diffusion chronometry across submicron crystal zones, ${ }^{73}$ and for developing alloy materials with desirable properties. ${ }^{2}$ However, the following challenges remain for this technology:

(1) Carbon accumulation and contamination due to the polymerization and deposition of hydrocarbon molecules around the analysis point absorbs the low energy X-rays. ${ }^{15,74}$ Plasma cleaning, gas cleaning, liquid nitrogen traps, and Peltier thermoelectric cooling devices can be used to mitigate the impact of carbon contamination. ${ }^{15,42,75,76}$ Replacing oil pumps with oil-free vacuum pumps can eliminate carbon contaminations at the source. ${ }^{2}$ In addition, some correction methods can be used to correct the carbon contamination effect. ${ }^{15}$

(2) The surface morphology of the samples, such as polishing quality, coating, and surface oxidation, can significantly affect analyses at low voltages because the electron beam cannot penetrate the sample deeply enough. ${ }^{74,77}$

(3) The L and M X-ray lines should be used at low voltages because high-energy $\mathrm{X}$-ray lines of elements are not generated at low accelerating voltages. The $\mathrm{L}$ and $\mathrm{M}$ lines are severely overlapped and interfered by the second and third order X-rays of other elements, ${ }^{78,79}$ making background analysis more difficult (Fig. 13). In addition, low X-ray intensity requires a long counting time and/or high beam current for the trace element analysis. $^{2}$

(4) For the first-row transition elements in the periodic table, their L lines are mostly low-energy X-rays that do not have well-determined mass absorption coefficients. Moreover, the chemical bonding and self-absorption result in severe peak shift for the L $\alpha$ signal, invalidating the traditional absorption correction. ${ }^{79-82}$ The methods proposed to address this issue include: a) correcting the matrix correction coefficient; ${ }^{83}$ b) replacing L $\alpha$ with L1 (M1-L3 transition); ${ }^{79,80,84}$ and c) combining curve correction with the area integration of $L \alpha$ and $L \beta .^{77,85}$ However, these solutions are only applicable for samples with simple compositions, such as olivine and ferroalloy, and the validity of samples with complex compositions still requires verification.

Iron oxidation state. The peak shift of $\mathrm{Fe} L \alpha$ and $\mathrm{Fe} \mathrm{L} \beta \mathrm{X}$-ray lines and change of $\mathrm{Fe} \mathrm{L} \alpha \mathrm{L} \beta$ intensity ratio were observed in the $\mathrm{Fe}^{3+} / \Sigma \mathrm{Fe}$ analysis with EPMA. The peak shift and intensity variation differ with the oxidation state. ${ }^{86}$ Hence, the $L \alpha$ and $L \beta$ of $\mathrm{Fe}^{2+}$ (such as almandine) and $\mathrm{Fe}^{3+}$ (such as andradite) may be distinguished and quantified in terms of their energies of $L$ lines (Fig. 14). The quantitative analysis of Fe oxides is based on the self-absorption correction, improved peak resolution, and matrix effect correction. Among these, self-absorption is the main influencing factor that depends on the $\mathrm{Fe}$ concentration and $\mathrm{Fe}$ L-line X-ray path length in the sample. ${ }^{87}$

The most commonly used method to obtain $\mathrm{Fe}^{3+} / \Sigma \mathrm{Fe}$ of samples is known as the "flank method," which involves a 
careful consideration of the peak positions of $L \beta$ and $L \alpha$ lines and $\mathrm{L} \beta / \mathrm{L} \alpha$ intensity ratio. ${ }^{86-93}$ The WDS spectrometers used are recalibrated based on the standards to strengthen the EPMA sensitivity for the "flank method". ${ }^{3}$ This calibration can avoid the $\mathrm{Fe}_{\text {total }}$ content interference and the self-absorption effect. ${ }^{93}$ Furthermore, this method measures the intensity ratios on the high- and the low-energy sides of $L \alpha$ and $L \beta$, respectively, and analyzes the $L \alpha$ and $L \beta$ peaks at the locations where the spectral differences are most significant (Fig. 14), thus considerably improve the sensitivity. ${ }^{87}$

Because the $\mathrm{Fe}^{2+}$ and $\mathrm{Fe}^{3+}$ self-absorption effects vary with minerals, the self-absorption effect of different minerals should be individually determined to establish a valid empirical correction model. The chemical composition of different end-members for garnet group minerals has no obvious effect on the $L / L \alpha$ ratio, indicating that the matrix effect is the same, and the "flank method" can be applied to different garnet end-members. ${ }^{87}$ The studies on the self-absorption effect of different minerals facilitates the application of the "flank method" to other materials, such as glass, ${ }^{89-92}$ hornblende, ${ }^{88}$ and biotite. ${ }^{88}$ However, suitable and appropriate standards with accurate $\mathrm{Fe}^{3+} / \Sigma \mathrm{Fe}$ values and establishment of specific "flank method" for different minerals are urgently required to promote the application of the "flank method" in determining $\mathrm{Fe}^{3+} / \Sigma \mathrm{Fe}$ by EPMA.

Standard reference materials. The standard reference materials used in EPMA include the primary standards and secondary standards. The primary standards are essential for every EPMA laboratory. Nevertheless, the primary standards used in different EPMA laboratories could vary. There are currently insufficient primary standards that can be applied in all EPMA laboratories. The absence of a global primary standards leads to a situation where we cannot reliably compare the quality of the quantitative results from different EPMA laboratories. Therefore, it is necessary to establish globally adopted, high-quality primary standards for most elements on the periodic table.

As discussed before, the quality of the EPMA results can be assessed using the analytical total or atomic ratios. However, it becomes difficult to use this approach to evaluate the quality of the trace element analyses. Therefore, suitable secondary standards are necessary for evaluating the analytical results. Moreover, it is effective to evaluate the results and find the problems by analyzing the secondary standards used under the same analytical conditions and sessions as the samples, for example, cross analyzing the secondary standards and unknown samples. In addition, blank references can be used for accurate background measurements. 22,23

Utilizing a secondary standard with its giving compositions similar to an unknown sample is always preferred. Unfortunately, such secondary standards are often missing, especially for the trace and light elements and for EPMA U-Th-Pbtotal dating. For example, for Ti analysis in quartz, a blank quartz reference ${ }^{22}$ with approximately 0 ppm of Ti and a quartz reference material ${ }^{94}$ with $57 \pm 4 \mathrm{ppm}$ of $\mathrm{Ti}$ can be used to measure the background and monitor the quality of the analytical results, respectively.

However, it could be beneficial to monitor the accuracy of the Ti analysis in quartz with secondary standards having low (such as 5 ppm) or relatively high (such as 100 ppm and 500 ppm) Ti content.

\section{CONCLUSIONS AND OUTLOOKS}

The past 70 years have witnessed widespread applications of EPMA in analyzing minerals or other materials for major, minor, trace, and light elements, for U-Th-Pb $b_{\text {total }}$ dating, and for determining the iron oxidation state. Improvement of hardware and software promotes the development of the analytical techniques of EPMA. For example, the availability of large diffracting crystals promotes the analyses of trace elements. Field emission gun enables high spatial resolution analysis, and implementing the latest soft X-ray analysis improves the analysis of light elements. The future progress of EPMA technology lies in: 1) further improvement of the instrument hardware and software, 2) optimization of the existing analysis methods, 3) development of practical methods for individual minerals and elements, 4) understanding the mechanism of interference factors and related issues, and 5) optimized matrix correction model. Developments, advances, and novel applications of EPMA techniques also require hardware manufacturers and instrument users to work together to address the challenges and difficulties encountered.

\section{AUTHOR INFORMATION}

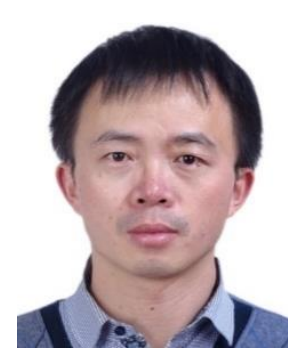

Shui-Yuan Yang is an associate professor of geosciences at the State Key Laboratory of Geological Processes and Mineral Resources, China University of Geosciences in Wuhan since 2013. He is also the lab manager of the EPMA. He worked as a visiting fellow at the Research School of Earth Sciences, Australian National University in 2020. He received a BSc in geochemistry (2008) and a $\mathrm{PhD}$ in mineralogy, petrology, and economic geology (2013) from the Nanjing University. His main topic of research is the use of elemental and isotopic geochemistry to reconstruct the genesis of granitoids (especially in South China) and its related uranium and REE deposits. He also focuses on the chemical and boron isotopic compositions of tourmaline and its implication in magmatism and related mineralization. A growing interest is the study of the analytical methods of EPMA and their applications to geosciences. 


\section{Corresponding Author}

*S.-Y. Yang

Email address: shuiyuanyang@cug.edu.cn

Notes

The authors declare no competing financial interest.

\section{ACKNOWLEDGMENT}

This research was funded by the National Key R\&D Program of China (2017YFC0601404), Natural Science Foundation of China (41773040), and Fundamental Research Funds for the Central University, China University of Geosciences (Wuhan) (CUGCJ1818). We are grateful to Prof. Wei Guo and four anonymous reviewers for providing valuable comments and suggestions, which helped in significantly improving this manuscript.

\section{REFERENCES}

1. R. Castaing. Application of electron probes to local chemical and crystallographic analysis. Ph.D. Thesis, Paris, University of Paris, 1951.

2. X. Llovet, A. Moy, P. T. Pinard, and J. H. Fournelle, Prog. Mater. Sci., 2021, 116, 100673. https://doi.org/10.1016/j.pmatsci.2020.100673

3. Zhao, Y. Zhang, and E. J. Essene, Ore Geol. Rev., 2015, 65, 733-748. https://doi.org/10.1016/j.oregeorev.2014.09.020

4. D. Zhang, Y. Chen, Q. Mao, B. Su, L. H. Jia, and S. Guo, Acta Petrol. Sin., 2019, 35, 261-274. https://doi.org/10.18654/1000-0569/2019.01.21

5. R. Rinaldi and X. Llovet, Microsc. Microanal., 2015, 21, 1053-1069. https://doi.org/10.1017/S1431927615000409

6. S. J. B. Reed, Electron Microprobe Analysis and Scanning Electron Microscopy in Geology, Cambridge University Press, 2005.

7. J. I. Goldstein, D. E. Newbury, P. Echlin, D. C. Joy, Jr. A. D. Romig, C. E. Lyman, C. Fiori, and E. Lifshin, Scanning Electron Microscopy and X-Ray Microanalysis: A Text for Biologists, Materials Scientists, and Geologists, Plenum Press, 1992.

8. T. R. Sweatman and J. V. P. Long, J. Petrol., 1969, 10, 332-379. https://doi.org/10.1093/petrology/10.2.332

9. H. G. J. Moseley, The London, Edinburgh, and Dublin Philosophical Magazine and Journal of Science, 1913, 26, 1024-1034. https://doi.org/10.1080/14786441308635052

10. JEOL Training Center. Practical Techniques for Microprobe Analysis. 1983.

11. S. P. Limandri, A. C. Carreras, and J. C. Trincavelli, Microsc. Microanal., 2010, 16, 583-593. https://doi.org/10.1017/S1431927610093761

12. D. M. Kerrick, L. B. Eminhizer, and J. F. Villaume, Am. Miner., 1973, 58, 920-925.
13. R. X. Zhang and S. Y. Yang, Microsc. Microanal., 2016, 22, 1374-1380. https://doi.org/10.1017/S143192761601182X

14. J. V. Smith, J. Geol., 1965, 73, 830-864.

15. B. Buse and S. Kearns, Microsc. Microanal., 2015, 21, 594-605. https://doi.org/10.1017/S1431927615000288

16. M. Raudsepp, Can. Mineral., 1995, 33, 203-218.

17. J. J. McGee and L. M. Anovitz, in: Boron: Mineralogy, Petrology, and Geochemistry, ed. L. M. Anovitz, and E. S. Grew, Mineralogical Society of America, Washington, D.C. 1996.

18. V. G. Batanova, A. V. Sobolev, and D. V. Kuzmin, Chem. Geol., 2015, 419, 149-157. https://doi.org/10.1016/j.chemgeo.2015.10.042

19. J. Q. Cui, S. Y. Yang, S. Y. Jiang, and J. Xie, Microsc. Microanal., 2019, 25, 47-57. https://doi.org/10.1017/S1431927618015672

20. R. X. Zhang, S. Y. Yang, S. Y. Jiang, and J. Xie, Microsc. Microanal., 2019, 25, 2362-2363. https://doi.org/DOI:10.1017/S1431927619012546

21. J. M. Allaz, M. L. Williams, M. J. Jercinovic, K. Goemann, and J. Donovan, Microsc. Microanal., 2019, 25, 30-46. https://doi.org/10.1017/S1431927618015660

22. J. J. Donovan, H. A. Lowers, and B. G. Rusk, Am. Miner., 2011, 96, 274-282. https://doi.org/10.2138/am.2011.3631

23. J. J. Donovan, J. W. Singer, and J. T. Armstrong, Am. Miner., 2016, 101, 1839-1853. https://doi.org/10.2138/am-2016-5628

24. E. Jarosewich, J. A. Nelen, and J. A. Norberg, Geostand. Newsl., 1980, 4, 43-47. https://doi.org/10.1111/j.1751-908X.1980.tb00273.x

25. X. Zhang, S. Y. Yang, H. Zhao, S. Y. Jiang, R. X. Zhang, and J. Xie, J. Earth Sci-China, 2019, 30, 834-842. https://doi.org/10.1007/s12583-017-0939-x

26. S. J. Lane and J. A. Dalton, Am. Miner., 1994, 79, 745-749.

27. E. J. Essene, Rev. Miner., 1983, 11, 77-96.

28. B. Goldoff, J. D. Webster, and D. E. Harlov, Am. Miner., 2012, 97, 1103-1115. https://doi.org/10.2138/am.2012.3812

29. M. Fialin and C. Chopin, Am. Miner., 2006, 91, 503-510. https://doi.org/10.2138/am.2006.1926

30. J. M. Pyle, F. S. Spear, and D. A. Wark, in Phosphates: geochemical, geobiological and materials importance, ed. M. J. Kohn, J. Rakovan, and J. M. Hughes, Mineralogical Society of America, Washington. 2002.

31. J. C. Stormer, M. L. Pierson, and R. C. Tacker, Am. Miner., 1993, 78, 641-648.

32. F. M. McCubbin, A. Steele, H. Nekvasil, A. Schnieders, T. Rose, M. Fries, P. K. Carpenter, and B. L. Jolliff, Am. Miner., 2010, 95, 1141-1150. https://doi.org/10.2138/am.2010.3448

33. C. Henderson, Microsc. Microanal., 2011, 17, 588-589. https://doi.org/10.1017/S1431927611003813

34. G. B. Morgan and D. London, Am. Miner., 1996, 81, 1176-1185.

35. G. B. Morgan and D. London, Am. Miner., 2005, 90, 1131-1138. https://doi.org/10.2138/am.2005.1769

36. S. L. Kearns, N. Steen, and E. Erlund, Microsc. Microanal., 2002, 8, 1562-1563. https://doi.org/10.1017/S1431927602107562

37. E. C. Hughes, B. Buse, S. L. Kearns, J. D. Blundy, G. Kilgour, and H. M. Mader, Chem. Geol., 2019, 505, 48-56. https://doi.org/10.1016/j.chemgeo.2018.11.015

38. S. Y. Yang, R. X. Zhang, S. Y. Jiang, and J. Xie, Geostand.Geoanal. Res., 2018, 42, 131-137. https://doi.org/10.1111/ggr.12199

39. D. Zhao, E. J. Essene, and Y. Zhang, Earth Planet. Sci. Lett., 1999, 166, 127-137. https://doi.org/10.1016/S0012-821X(98)00281-7 
40. R. Q. Wu, C. Rao, Q. Wang, and D. Zhang, Chin. Sci. Bull., 2020, 65, 2161-2168. https://doi.org/10.1360/TB-2020-0082

41. W. L. Zhang, X. D. Che, R. C. Wang, L. Xie, X. F. Li, and Di Zhang, Chin. Sci. Bull., 2020, 65, 3205-3216. https://doi.org/10.1360/TB-2020-0316

42. B. Buse, S. Kearns, C. Clapham, and D. Hawley, Microsc.Microanal., 2016, 22, 981-986. https://doi.org/10.1017/S1431927616011715

43. G. F. Bastin and H. J. M. Heijligers, X-Ray Spectrom., 1986, 15, 135-141.

44. G. F. Bastin and H. J. M. Heijligers, J. Solid State Chem., 2000, 154, 177-187. https://doi.org/10.1006/jssc.2000.8832

45. L. Cheng, C. Zhang, X. Li, R. R. Almeev, X. Yang, and F. Holtz, Microsc. Microanal., 2019, 25, 874-882. https://doi.org/10.1017/S1431927619014612

46. A. von der Handt, J. Mosenfelder, C. Dalou, and M. M. Hirschmann, Microsc. Microanal., 2019, 25, 2320-2321. https://doi.org/10.1017/S1431927619012339

47. T. Ogiwara, T. Kimura, S. Fukushima, K. Tsukamoto, T. Tazawa, and S. Tanuma, Microchim. Acta, 2008, 161, 451-454. https://doi.org/10.1007/s00604-007-0877-x

48. A. Kronz, A. M. Van den Kerkhof, and A. Müller, in Quartz: Deposits, Mineralogy and Analytics, ed. J. Götze, and R. Möckel, Springer, Berlin, Heidelberg. 2012.

49. M. J. Jercinovic, M. L. Williams, J. Allaz, and J. J. Donovan, IOP Conf. Ser.: Mater. Sci. Eng., 2012, 32, 12012. https://doi.org/10.1088/1757-899X/32/1/012012

50. M. Fialin, H. Remy, C. Richard, and C. Wagner, Am. Miner., 1999, 84, 70-77. https://doi.org/10.2138/am-1999-1-207

51. J. Q. Cui, S. B. Guo, R. X. Zhang, J. Xie, and S. Y. Yang, Geol. J. China Univ., 2021, 27, 340-348. https://doi.org/10.16108/j.issn1006-7493.2021035

52. M. J. Jercinovic and M. L. Williams, Am. Miner., 2005, 90, 526-546. https://doi.org/10.2138/am.2005.1422

53. X. Llovet, J. A. Proenza, N. Pujol-Solà, J. Farré-de-Pablo, and M. Campeny, Microsc. Microanal., 2020, 1-11. https://doi.org/DOI: 10.1017/S1431927620024393

54. A. Y. Borisova, N. R. Zagrtdenov, M. J. Toplis, J. J. Donovan, X. Llovet, P. D. Asimow, P. de Parseval, and S. Gouy, Chem. Geol., 2018, 490, 22-29. https://doi.org/10.1016/j.chemgeo.2018.05.010

55. J. Fournelle, Microsc. Microanal., 2007, 13, 1390-1391. https://doi.org/10.1017/S1431927607079354

56. M. L. Williams, M. J. Jercinovic, K. H. Mahan, and G. Dumond, Rev. Miner. Geochem., 2017, 83, 153-182. https://doi.org/10.2138/rmg.2017.83.5

57. K. Suzuki and T. Kato, Gondwana Res., 2008, 14, 569-586. https://doi.org/10.1016/j.gr.2008.01.005

58. K. Suzuki and M. Adachi, Geochem. J., 1991, 25, 357-376.

59. J. F. W. Bowles, Chem. Geol., 1990, 83, 47-53. https://doi.org/10.1016/0009-2541(90)90139-X

60. J. Montel, S. Foret, M. Veschambre, C. Nicollet, and A. Provost, Chem. Geol., 1996, 131, 37-53. https://doi.org/10.1016/0009-2541(96)00024-1

61. D. Rhede, I. Wendt, and H. J. Förster, Chem. Geol., 1996, 130, 247-253. https://doi.org/10.1016/0009-2541(96)00015-0

62. J. M. Allaz, M. J. Jercinovic, and M. L. Williams, IOP Conf. Ser.: Mater. Sci. Eng., 2020, 891, 12001. https://doi.org/10.1088/1757-899X/891/1/012001
63. J. Q. Cui, S. Y. Yang, S. Y. Jiang, and J. Xie, Microsc. Microanal., 2019, 25, 2364-2365. https://doi.org/DOI: 10.1017/S1431927619012558

64. P. Konečný, M. A. Kusiak, and D. J. Dunkley, Chem. Geol., 2018, 484, 22-35. https://doi.org/10.1016/j.chemgeo.2018.02.014

65. L. Strüder, C. Fiorini, E. Gatti, R. Hartmann, P. Holl, N. Krause, P. Lechner, A. Longoni, G. Lutz, J. Kemmer, N. Meidinger, M. Popp, H. Soltau, and C. von Zanthier. In: 5th Workshop of the European-Microbeam-Analysis-Society on Modern, ed. G. Love, W. A. P. Nicholsonand A. and Armigliato eds, Springer Vienna, Vienna. 1998:11-19.

66. D. E. Newbury and N. W. M. Ritchie, J. Mater. Sci., 2015, 50, 493-518. https://doi.org/10.1007/s10853-014-8685-2

67. A. V. Villa, B. Bruck, and J. Fournelle, Microsc. Microanal., 2020, 26, 1548-1551. https://doi.org/10.1017/S1431927620018486

68. D. E. Newbury and N. W. M. Ritchie, Microsc. Microanal., 2019, 25, 1075-1105. https://doi.org/10.1017/S143192761901482X

69. E. S. Bullock, Microsc. Microanal., 2018, 24, 792-793. https://doi.org/10.1017/S1431927618004452

70. D. E. Newbury and N. W. M. Ritchie, Scanning, 2013, 35, 141-168. https://doi.org/10.1002/sca.21041

71. H. E. Çubukçu, O. Ersoy, E. Aydar, and U. Çakir, Micron, 2008, 39, 88-94. https://doi.org/10.1016/j.micron.2006.11.004

72. M. Briant and D. Balloy, Eur. Phys. J.-Appl. Phys., 2008, 44, 37-42. https://doi.org/10.1051/epjap:2008146

73. K. Saunders, B. Buse, M. R. Kilburn, S. Kearns, and J. Blundy, Chem. Geol., 2014, 364, 20-32. https://doi.org/10.1016/j.chemgeo.2013.11.019

74. C. Merlet and X. Llovet, IOP Conf. Ser.: Mater. Sci. Eng., 2012, 32, 12016. https://doi.org/10.1088/1757-899x/32/1/012016

75. P. T. Pinard, A. Schwedt, A. Ramazani, U. Prahl, and S. Richter, Microsc. Microanal., 2013, 19, 996-1006. https://doi.org/10.1017/S1431927613001554

76. T. Yamashita, Y. Tanaka, M. Nagoshi, and K. Ishida, Sci. Rep., 2016, 6, 29825. https://doi.org/10.1038/srep29825

77. A. Moy, J. H. Fournelle, and A. V. D. Handt, Am. Miner., 2019, 104, 1131-1142. https://doi.org/doi:10.2138/am-2019-6865

78. V. Mikli, Microchim. Acta, 2006, 155, 205-208. https://doi.org/10.1007/s00604-006-0544-7

79. P. T. Pinard and S. Richter, IOP Conf. Ser.: Mater. Sci. Eng., 2016, 109, 12013. https://doi.org/10.1088/1757-899x/109/1/012013

80. P. Gopon, J. Fournelle, P. E. Sobol, and X. Llovet, Microsc.Microanal., 2013, 19, 1698-1708. https://doi.org/10.1017/S1431927613012695

81. P. Jonnard, F. Brisset, F. Robaut, G. Wille, and J. Ruste, X-Ray Spectrom., 2015, 44, 24-29. https://doi.org/10.1002/xrs.2573

82. X. Llovet, E. Heikinheimo, A. N. Galindo, C. Merlet, J. F. A. Bello, S. Richter, J. Fournelle, and C. J. G. van Hoek, IOP Conf. Ser.: Mater. Sci. Eng., 2012, 32, 12014. https://doi.org/10.1088/1757-899x/32/1/012014

83. B. Buse and S. Kearns, Microsc. Microanal., 2018, 24, 1-7. https://doi.org/10.1017/S1431927618000041

84. X. Llovet, P. T. Pinard, E. Heikinheimo, S. Louhenkilpi, and S. Richter, Microsc. Microanal., 2016, 22, 1233-1243. https://doi.org/10.1017/S1431927616011831

85. A. Moy, J. Fournelle, and A. von der Handt, Microsc. Microanal., 2019, 25, 664-674. https://doi.org/10.1017/S1431927619000436

86. H. E. Höfer, G. P. Brey, B. Schulz-Dobrick, and R. Oberhänsli, Eur. J. Mineral., 1994, 6, 407-418. 
87. H. E. Höfer and G. P. Brey, Am. Miner., 2007, 92, 873-885. https://doi.org/10.2138/am.2007.2390

88. X. Li, C. Zhang, R. R. Almeev, X. C. Zhang, X. F. Zhao, L. X. Wang, J. Koepke, and F. Holtz, Chem. Geol., 2019, 509, 152-162. https://doi.org/10.1016/j.chemgeo.2019.01.009

89. C. Zhang, R. R. Almeev, E. C. Hughes, A. A. Borisov, E. P. Wolff, H. E. Höfer, R. E. Botcharnikov, and J. Koepke, Am. Miner., 2018, 103, 1445-1454. https://doi.org/10.2138/am-2018-6437

90. M. Fialin, C. Wagner, and M. L. Pascal, Mineral. Mag., 2011, 75, 347-362. https://doi.org/10.1180/minmag.2011.075.2.347

91. M. Fialin, A. Bézos, C. Wagner, V. Magnien, and E. Humler, Am. Miner., 2004, 654-662, 654-662. https://doi.org/10.2138/am-2004-0421
92. M. Fialin, C. Wagner, N. Métrich, E. Humler, L. Galoisy, and A. Bézos, Am. Miner., 2001, 86, 456-465. https://doi.org/10.2138/am-2001-0409

93. H. E. Höfer, S. Weinbruch, C. A. Mccammon, and G. P. Brey, Eur. J. Mineral., 2000, 12, 63-71. https://doi.org/10.1127/0935-1221/2000/0012-0063

94. A. Audétat, D. Garbe-Schönberg, A. Kronz, T. Pettke, B. Rusk, J. J. Donovan, and H. A. Lowers, Geostand. Geoanal. Res., 2015, 39, 171-184. https://doi.org/10.1111/j.1751-908X.2014.00309.x 